\title{
La teoría del lenguaje de Vygotsky y la filosofía del espíritu de Hegel ${ }^{1}$
}

\section{Vygotsky's theory of language and Hegel's philosophy of the spirit}

\author{
Luis Velarde ${ }^{2}$
}

\begin{abstract}
Resumen
Este trabajo presenta una interpretación de la teoría del lenguaje de Vygotsky en el marco de las implicaciones de la filosofía del espíritu de Hegel. Se busca revelar que el lenguaje es un modo de unidad de universal y singular, o bien de sociedad e individuo, en cuyo seno no caben los extremos que escindan sin mediación cada momento de la relación. El lenguaje, de este modo, se presenta como un modelo de comprensión de nociones como unidad de práctica y teoría o voluntad racional, permitiendo asumir la participación inherente de los elementos socio-históricos en los procesos de individuación sin pretendidas originalidades ontológicas ni saltos insalvables entre una esfera y otra. Para este fin, se analiza sumariamente la filosofía hegeliana en relación con el lenguaje y el espíritu. Luego se destacan argumentaciones diversas sobre el papel constructivo del lenguaje en relación con la comprensión del mundo. Finalmente, se expone la teoría del lenguaje de Vygotsky y los posibles aportes de inteligibilidad interpretados desde la filosofía de Hegel.
\end{abstract}

Palabras clave: Espíritu, lenguaje, funciones psíquicas superiores, voluntad, individuo.

\begin{abstract}
This article presents an interpretation of Vygotsky's theory of language within the framework of the implications of Hegel's philosophy of the spirit. It seeks to reveal that language is a mode of universal and singular unity, or of social and individual, within which there is no room for extremes that separate them without mediating the relationship. Language is thus presented as a model to understand notions as unity of practice and theory or rational volition, allowing us to assume the inherent participation of the sociohistorical elements in individualisation processes. This model does not assume ontological originalities or insurmountable leaps between one sphere and the other. To this end, Hegelian philosophy is summarily discussed in relation to language and spirit. Various arguments are then highlighted on the constructive role of language in understanding the world. Finally, Vygotsky's theory of language and the possible contributions of intelligibility, interpreted from Hegel's philosophy, are presented.
\end{abstract}

Key words: Spirit, language, higher psychological processes, will, individual.

\footnotetext{
${ }^{1}$ Profesor de Lengua y Literatura en Centro Educacional Jean Jacques Rousseau, Santiago, Chile.

${ }^{2}$ Magister en Literatura Latinoamerica, USACH. Correo electrónico: luis.velarde.f@ gmail.com
} 


\section{Presentación}

Aunque la propia naturaleza científica de las investigaciones lingüísticas desestima una teorización omniabarcante de sus resultados aplicados al estatuto humano o a la inteligibilidad de la experiencia humana, sus conceptos y cuerpos teóricos no han evitado integrar argumentaciones filosóficas, desde Humboldt en adelante (Cassirer, 2016, pp.40, 91 ss.), aunque, como Chomsky ha señalado, la literatura filosófica contemporánea cuando se hace cargo de la relación entre lenguaje y pensamiento, por ejemplo, incluyendo el enfoque antropológico de la hipótesis SapirWorff, resulta poco convincente (Wright, 2007). Baste pensar en la idea según la cual la determinación lingüística constituye un a priori fuera del cual no solo ni pensamiento ni cultura tendrían lugar, sino que éstos serían meras proyecciones de la naturaleza del lenguaje. No es de otro modo como puedan entenderse aserciones como la de Heidegger cuando afirma que es el lenguaje el que nos habla, más allá de su apariencia de ser instrumento nuestro (1994, p.165).

Asimismo, el llamado "giro lingüístico" no contribuyó solo a una nueva inteligibilidad del ser social (Lefebvre, 1967), ni solo a destacar el papel activo del lenguaje, sino a ofrecer sustento a posturas que aseguran que la conciencia o el sujeto son accidentes o meras mistificaciones ideológicas (Habermas, 1990, p. 58), efectos de estructuras profundas, como puede notarse en el materialismo discursivo, según la denominación de Žižek (2015). Badiou (2014), por su parte, llama sofistica contemporánea a toda la corriente de pensamiento que se caracteriza por destacar los límites lingüísticos del pensamiento y proponer escapes formales.

Pues bien, sostenemos que lo crucial en juego tras estas aserciones estriba en el viejo problema de la relación entre individuo y sociedad. Cuando admitimos que el individuo recibe influjo del medio social, suponemos que aquel ya es sustancialmente fuera de éste, como si no existiese de suyo como integrante del medio social. A su vez, si el individuo se explica por su medio, por ejemplo, en su volición, no es menos cierto, entonces, que su calidad subjetiva no encuentra sustento más que como mera ideología, del modo como proponen estructuralismo y posestructuralismo. Y, sin embargo, nociones como responsabilidad y libertad, requieren del trabajo subjetivo y la conducta consciente. Así pues, tan pronto nos enfocamos en el rol activo de lo universal, perdemos lo singular, y viceversa. En este escenario no es extraño que lo individual o la diferencia aparezcan como tensión imponderable, arbitrariedad, discontinuidad, entre otros.

El presente trabajo busca destacar que la totalidad social no es un más allá del individuo, ni éste puede ser concebido solo como una cáscara inesencial, apenas aparente. Nos basamos para esto en los aportes hegelianos a una lógica que hace de la negatividad lo esencial de la sustancia y desde la cual pueden entenderse los aportes en psicolingüística de Vygotsky, quien ha sido reconocido por su contribución en el ámbito del individuo (Seve 2013), pese a que en general sea considerado principalmente en pedagogía.

Nuestra tesis general es: la filosofía del espíritu de Hegel confiere inteligibilidad a la teoría del lenguaje de Vygotsky, a condición de que se atienda a la coincidencia entre el historicismo radical del filósofo alemán y su idea de integración de universal y singular, por un lado, y el programa del autor ruso enfocado en el origen y carácter histórico de las funciones psíquicas superiores mediadas lingüísticamente, además de su implicación en el proceso de individuación, por otro. En este marco común del problema, sostendremos particularmente que la teoría del lenguaje de Vygotsky permite entender la idea de voluntad racional y, por otro lado, la calidad subjetiva del concepto se entiende en la unidad de intelecto y voluntad. Esperamos contribuir de esta forma a la dilucidación del problema acerca del relativismo epistemológico e historicismo implicados en la tesis de Vygotsky sobre el carácter histórico y cultural de los 
procesos psíquicos superiores (Cole \& Wertsch, 1996), principalmente a partir del deslinde entre las acciones genuinamente humanas del ser social, esto es, cuando la conciencia deja de ser un epifenómeno de la actividad productiva y reproductiva, así como también a través del énfasis en la relación de "ser superado" propio de la lógica hegeliana.

Con dicho objetivo iniciamos por destacar sumariamente los antecedentes hegelianos acerca del lenguaje y, por sobre todo, su filosofía del espíritu. Continuamos recogiendo en general las posturas sobre el papel activo del lenguaje ya sea entendido como un incondicionado que determina nuestra conciencia y cultura, ya sea destacando el impacto de lo social en el pensamiento, donde, en cualquier caso, la voluntad no aparece desempeñando un papel significativo. Luego veremos lo esencial al respecto en la teoría de Vygotsky. Finalmente, repasamos los análisis realizados.

\section{Antecedentes hegelianos}

\section{El lenguaje en Hegel}

En los primeros escritos en que Hegel aborda el lenguaje, éste aparece, junto a los ámbitos del trabajo y la interacción social, como una dimensión del espíritu. Habermas ha señalado que se puede observar en ellos "modelos de construcción del movimiento dialéctico" (2015a, p.40), en que el espíritu no consigue su verdad previamente a su desarrollo en lo existente, esto es, no hay un estado trascendental que solo se manifieste en la experiencia, sino que en ella misma el espíritu se forma y adquiere sus contenidos. Por ello, Taylor (2014) ha caracterizado la concepción de Hegel como "expresivista", por cuanto concibe la inseparabilidad del contenido de su soporte material. Hegel habría seguido a Herder en su noción de irreductibilidad del contenido a un aspecto suyo que lo escinda de la manera de presentarse. Al contrario, este presentarse sería el contenido y, por ende, solo podría explicarse en su exposición. De esta manera Hegel asume la unidad de infinito y finito, el acceso consciente a lo absoluto.

En Filosofía real, Hegel muestra que el proceso de individuación, caracterizado por la conciencia de sí en tanto sujeto, se halla en estrecha unidad con la condición mediante la cual se accede a los objetos en el lenguaje, pues en éste se alcanza la estabilidad del nombre, como generalidad de la cosa, elemento necesario para que la conciencia asuma su propia actividad. "La conciencia hablante se hace a sí misma objetiva por medio de ellos [de los símbolos], y en ellos tiene experiencia de sí como de un sujeto" (Habermas, 2015a, p.27-28). De manera semejante, en la Enciclopedia de las ciencias filosóficas Hegel incluye al lenguaje como momento en que el espíritu descubre los contenidos dados de su propia naturaleza como viviente, asumiéndolos para sí como objetividad ideal.

En efecto, en la sección de la Enciclopedia destinada a la psicología, el lenguaje aparece en la esfera teorética permitiendo al yo apropiarse intelectualmente del mundo como condición del yo práctico, la voluntad. Del mismo modo que en Filosofía real, aquí el lenguaje desempeña el papel de interiorización, haciendo de la inmediatez de la objetividad del espíritu, algo propio de su subjetividad. Por ejemplo, Hegel trata al signo como algo intuido en tanto ser superado, cuya alma, el significado, libera al espíritu de la inmediatez, la dispersión accidental de lo simplemente dado, a fin de concebir la generalidad del contenido. Así, al analizar las formas concretas que asumen los símbolos gráficos del lenguaje, dice: 
...un simple signo inmediato que como un ser de por sí no ofrece nada que pensar y sólo tiene la determinación de significar la simple representación en cuanto tal y representarla sensiblemente. La inteligencia que representa no hace solamente eso, el demorarse en la simplicidad de las representaciones como igualmente condensarlas a partir de los momentos más abstractos en que fueron analizadas, sino que el pensar resume también bajo la forma de un pensamiento simple el contenido concreto [de la representación] partiendo del análisis en el que ese contenido se convirtió [primero] en un conjunto de muchas determinaciones. (1999, p.504)

La palabra se intuye en relación directa con su significado. "Es en el nombre donde pensamos" (Hegel, 1999, p.506). Lo que significa que el signo lingüístico es ser superado; es la condición en sí del pensamiento. Hegel ve, pues, en el lenguaje la actividad de la inteligencia que, en virtud de que sus productos no son solo la afirmación de su sustancia, sino también la negación de ésta, despliegan un contenido cualitativamente nuevo, irreductible a su mero ser inmediato: un pensamiento que interioriza y subjetiviza lo dado.

Asimismo, Hegel confiere al lenguaje su importancia en el marco del espíritu, es decir, como un momento de la actividad social, ámbito en el cual la calidad subjetiva se abre camino. Esto puede colegirse de la versión de 1803/04 de Filosofía real, en cuya sección sobre el espíritu de un pueblo se hacía referencia al idioma en los siguientes términos:

El lenguaje solo es como lenguaje de un pueblo, y lo mismo el entendimiento y la razón. Sólo como obra de un pueblo es el lenguaje la existencia ideal del Espíritu, en la que éste se expresa a sí mismo lo que es por esencia y en su ser. El lenguaje es algo general, reconocido implícitamente, resuena de un solo modo en la conciencia de todos; en él cada conciencia parlante se convierte inmediatamente en otra conciencia. (p.323, nota 182/22) ${ }^{3}$

\section{Lecturas acerca del lenguaje en Hegel}

Siguiendo a Iliénkov (2017), se puede afirmar que la lectura de Hegel realizada por la hermenéutica contemporánea confiere un lugar central al lenguaje debido a que ve en él la estructura universal de la existencia. Así, por un lado, Gadamer sugiere que por medio del lenguaje Hegel desentraña los contenidos lógico-universales correspondientes a la efectividad del espíritu de implicancias ontológicas. Hegel habría revelado el elemento especulativo del instinto lógico del lenguaje, de tal manera que "lo especulativo solamente es real cuando no es solamente retenido en la interioridad del mero opinar, sino que alcanza a cobrar expresión [...] en la velada tensión del espíritu del lenguaje prevalente entre nosotros" (Gadamer, 2011, p.46). Esto significa que en el lenguaje se hallaría una manifestación del espíritu, en cuya realización se accede a su estructura ontológica. Por otro lado, Simon (1982) sostiene que el movimiento dialéctico de las figuras de la conciencia en la Fenomenología de Hegel, se encuentra dinamizado por el carácter inherentemente lingüístico de ésta. La "lingüisticidad" revelaría la vocación universal de conciencia como comunidad hablante, el yo que es nosotros y el yo que debe exponer su verdad ante otro. La lectura que hace la hermenéutica del lenguaje en Hegel, entonces, acentúa la presencia ontológica del espíritu incubada en esta esfera. Luego, cada ente particular no hace sino

${ }^{3}$ Cursivas y negritas en el original.

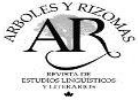


actualizar la dimensión ontológico-universal del espíritu, en un sentido originario, tan pronto ejerza su actividad comunicativa, tanto más cuanto se considere al lenguaje develando al ser. ${ }^{4}$ Esto debe entenderse menos desde la subjetividad, mediante la cual se arbitra conceptualmente sobre los entes, que desde una pretendida anterioridad presente, aunque oculta, del ser.

Por otro lado, la lectura de Taylor (2014) ha destacado el carácter expresivista del concepto hegeliano de lenguaje. Vinculado al espíritu, el lenguaje no se deja reducir, como ninguna actividad cultural, a su base psicofísica. Antes bien, como expresión del pueblo, tiene un carácter formativo en las representaciones que el colectivo tiene del mundo. Según Taylor, los rasgos principales de la filosofía del espíritu de Hegel, de la cual deriva su noción del lenguaje, son las dimensiones efectiva y expresiva, esto es, lo real es resultado y solo puede darse en un medio de comprensión, respectivamente. "Cada formación de vida de la historia es a la vez la realización efectiva de cierto patrón y la expresión de sí del hombre y por tanto también del espíritu" (2005, p.111). Así pues, cabe entender el hecho de que Hegel incluya el desarrollo del lenguaje en la esfera del espíritu teorético, es decir, como captación intelectual del mundo, ya que en él se expresan los contenidos universales de lo absoluto, más allá de la mera individualidad del hablante. Hegel mismo señaló en la Enciclopedia que la parte menos espiritual del lenguaje debía estudiarse en la antropología o la psicofisiología, pero que el aspecto formal en relación con la gramática, por cuanto participa del intelecto, se vincula a la universalidad del espíritu y en esta medida supera su mera aparición exterior, conectándose con el devenir histórico.

Podemos observar, por lo tanto, que tanto el expresivismo como la hermenéutica comparten un punto de vista. Si el lenguaje se considera en su elemento teorético, se vincula con la representación en cuanto señala una relación con los objetos. Que dicha relación sea expresión de una cosmovisión como el expresivismo o si se la asume como estructura ontológica, no cambia el sentido general de la idea de que el lenguaje representa el pensamiento, por cuanto en él se encuentran los contenidos universales. En una versión expresa una forma de ser de un pueblo; en otra esconde las categorías lógicas pero que a la vez le dan existencia efectiva en la vida de la comunidad hablante; por último, determina esencialmente la conciencia como totalidad y jalona su saber hacia lo absoluto. Estas interpretaciones demuestran la importancia de lo universal en la conciencia, pero lo han determinado en las representaciones u operaciones presentes en nuestra comprensión del mundo. Hegel mismo indica el papel general del lenguaje en marcas determinables: a) en el lenguaje se logra la primera separación de sujeto y objeto; b) por cuanto el lenguaje permite el pensamiento, prepara la condición para la acción práctica (el deseo); c) el lenguaje consiste en el trabajo del espíritu y se debe comprender en esta índole, d) el lenguaje llega a su verdad en la comunidad lingüística.

\section{La filosofía del espíritu de Hegel}

Aunque la idea de Hegel según la cual en la obtención del objeto, es decir que en su dominio a través del nombre se logra a la vez la condición de sujeto, es importante en virtud de su similitud con la teoría del lenguaje de Vygotsky, queremos destacar el marco general de la filosofía del espíritu, por cuanto a partir de ella se puede establecer el nexo de inteligibilidad respecto de los hallazgos del autor ruso.

Para Hegel la subjetividad y libertad encuentran su más alta realización en el espíritu, esto es, "la definición suprema de lo absoluto" (Hegel, 1999, p.437). A fin de comprender la

\footnotetext{
${ }^{4}$ Ver análisis del tema ontológico del lenguaje en la hermenéutica heideggeriana en Adorno (2017).
}

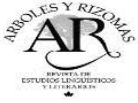


profundidad de esta aserción y su vínculo con el materialismo histórico de Vygotsky cabe enfatizar dos de sus aspectos. Primero, el concepto de espíritu de Hegel se encuentra situado en la realidad misma: "el espíritu -la razón- nunca existe como una cosa, sino que debe ser producido por la actividad común del sujeto y del mundo" (Labrarriere, 1985, p.158). En consonancia con el doble rechazo que realiza el filósofo, a saber, ver en la materia sensible la mera sustancia de la cual emergen afirmativamente las diversas acciones del espíritu como pura extensión e, igualmente, hacer de las acciones del espíritu expresiones de facultades previas, desdeñando los contenidos desplegados en su objetividad (Hegel, 1999, p.485), las determinaciones particulares del espíritu son su modo efectivo de ser, sin las cuales no cabe hablar de su carácter absoluto. Así, por ejemplo, el saber que se efectúa en la Fenomenología consiste en "contemplar cómo, intrínsecamente, un contenido se despliega de hecho y sin resto y como una serie formal, hasta que el contenido absoluto [...] coincide uno intuitu con la forma absoluta, conceptual: la sustancia es precisamente y en el mismo sentido sujeto" (Duque, 2015, p.535) ${ }^{5}$. Luego, el espíritu no es un demiurgo indiferente a la existencia histórica, antes al contrario, el espíritu es este mismo despliegue histórico.

El segundo aspecto a destacar estriba en que el espíritu no es universal en el sentido cuantitativo, solo como promedio indiferente de los entes diversos, sino que es universal e infinito pues comprende en sí mismo la finitud. "Se puede llamar «espíritu»-dijo Hegel en su juventud- a la vida infinita, en oposición a la multiplicidad abstracta, puesto que «espíritu» es la unión concordante, viviente, de lo múltiple, en oposición a lo múltiple en cuanto configuración [propia] (que constituye la multiplicidad incluida en el concepto de vida)" (Cit. en Duque, 2015, p.360). En este sentido, Lukács (1969, p.47-82) señaló que las categorías de infinitud y universalidad de Hegel tienen un valor cualitativo. Asimismo, se ha enfatizado que en el monismo hegeliano "lo finito es en la medida en que lo absoluto es; y lo absoluto es él mismo en cuanto éste se autoelimina" (Heinrich, 1990, p.246). De tal manera que la susbsunción formal y cuantitativa de los entes en la universalidad se evita a través de la integración de la negatividad en el propio ser de lo infinito. Así, pues, solo "la totalidad es sujeto como tal. El sujeto en sentido particular es real, sin embargo, por el modo negativo como la totalidad se hace a sí misma" (Pérez Soto, 2008a, p.178).

Si consideramos el espíritu hegeliano como la totalidad social de la cual participan los individuos, se hace patente que el asunto puede tematizarse conforme al tópico de la relación de integración de individuo y sociedad. Ya Marcuse ha visto en la filosofía hegeliana este mismo tema cuando comenta: "Las más altas potencialidades de la humanidad radican en la unión racional de individuos libres, es decir, en la universalidad, y no en particularidades fijas. El individuo solamente puede aspirar a realizarse si es miembro libre de una verdadera comunidad" (Marcuse, 20017, p.114 ${ }^{6}$ ). En este ámbito lo que está en juego consiste en comprender la manera en que la misma individualidad es social e histórica pero que a la vez ella por cuanto es individualidad no se subsume sin más en lo social, prescindiendo de la voluntad y la conciencia. Es claro que tan pronto tomamos el punto de vista de lo social, pensamos la individualidad como resultado, determinada socialmente y, en este sentido, o bien el yo individual es externo a la sociedad o simplemente expresa los contenidos sociales. Mientras que si nos posicionamos en el punto de vista de la conciencia y su autonomía, no podemos menos que considerarla irreductible a lo social, como un reducto de voluntad incondicionada, al modo kantiano. Así la dificultad estriba en la disyunción acerca de lo condicionado e incondicionado.

${ }^{5}$ Cursivas del autor.

${ }^{6}$ Cfr. también Valls-Plana (1994).

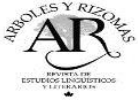


Pues bien, la filosofía del espíritu de Hegel propone una lógica distinta de pensar esta dicotomía merced a la negatividad que habita la universalidad, una totalidad cuya actividad es la autonegación, lo que también se entiende como particularización, conforme a la famosa aserción de Spinoza. Y es que la concreción misma de lo universal consiste en su particularización, su autonegación. "Los particulares como momentos del universal se encuentran 'ya' en el universal abstracto, pero no puestos o, para decirlo aristotélicamente, están en potencia” (Dri, 2007, p. 60). Cabe colegir de esto que la negatividad, la particularidad, conlleva la integración de universal y singular, de manera tal que su relación es recíprocamente fundante. Lo absoluto, lo incondicionado realmente puede ser solo aquello cuyo límite viene de sí mismo, por tanto es interior diferencia. Desde el punto de vista formal se dirá que la diferencia procede de la misma identidad y solo en su relación son concebibles. Por ejemplo, siguiendo el comentario de Félix Duque, al pensar el principio de contradicción, este incluye dos proposiciones unidas en el principio de tercero excluso, es decir que $\mathrm{A}=\mathrm{A}$ y $\mathrm{A}$ es distinta $\mathrm{a}-\mathrm{A}$, fuera de esto parece evidente que no hay otra opción. Pero resulta que

A lo es solamente cuando es «puesta» (literalmente: afirmada) como «negando» todo lo demás (que, a su vez, la niega: niega ser A). Luego A no es absolutamente $|\mathrm{A}|$, sino en realidad: $+\mathrm{A}$. Y por ende, es solo una «parte» de sí misma (ella es ella misma sólo si se le añade la negación: $-\mathrm{A}$; es decir «A=A» si «+A $\left.{ }^{\wedge}-\mathrm{A} »\right)$. (Duque, 2015, p. 443)

No es que exista una diferencia que surge desde afuera, como queda claro en la cita de Duque, más bien la propia identidad incluye en su interior la diferencia para poder ser. Así, "cada miembro, para ser él mismo (para ser «en sí»), ha de ser, no solamente «el otro», sino «el o lo otro de sí mismo»" (Duque, 2015, p. 443).

En el marco de las reflexiones acerca de la sociedad y los desafíos teóricos de la revolución francesa ${ }^{7}$, Hegel desarrolló un concepto de espíritu cuya lógica viene determinada por la integración de los extremos de una conciencia autónoma e individual, por un lado, y de una formación social ${ }^{8}$, por otro, ámbito en el cual puede realmente pensarse la mutua implicación del ser social y el ser individual, sin caer en la pura determinación ni en el puro solipsismo egoísta.

\section{El carácter activo del lenguaje en relación con el pensamiento}

La aserción según la cual el lenguaje cumple un papel constructivo en las representaciones del mundo se origina al menos desde las teorías de Humboldt y Herder y se encuentran expuestas por autores de corrientes disímiles como el materialismo histórico, el idealismo y el neopositivismo. En general concuerdan en el rechazo a la postura designativa que afirma un carácter reflejo y pasivo de los objetos del mundo y la conciencia. Así, cuando Schaff (1967) analiza los posicionamientos teóricos acerca de la relación entre lenguaje y conocimiento, destaca los inicios de la lingüística en las filosofías de Herder y Humboldt, quienes propusieron de formas distintas que existe una comprensión del mundo implícita en la lengua de un pueblo, en la cual se expresa su cultura, implicando, por cierto, que la subjetividad determina el acceso a la realidad.

\footnotetext{
${ }^{7}$ Ver los textos de Habermas (2015b) "La crítica de Hegel a la revolución francesa” y “A propósito de los escritos políticos de Hegel" en Teoría y praxis. Madrid: Tecnos.

${ }^{8}$ Se puede seguir un modelo de análisis de integraciones de estos extremos en las Lecciones de estética de Hegel, op.cit.
} 
El extremo de esta aserción puede encontrarse en la concepción de un a priori lingüístico, al modo de las categorías kantianas, es decir, el lenguaje como creador de mundo. En este sentido Schaff puede ligar teorías disímiles en otros aspectos, a saber, la filosofía de las formas simbólicas de Cassirer (2016) y el convencionalismo neopositivista. La primera postula la existencia de formas simbólicas como construcciones del mundo de los objetos por parte del espíritu. Éstas crean diferentes imágenes del mundo según sus productos espirituales: el lenguaje, el mito, el arte y el conocimiento científico; "[D]e este modo, el lenguaje, que es la forma simbólica fundamental -pues tanto el mito como la ciencia se sirven del lenguaje- se concibe como una energía propia del espíritu que crea apriorísticamente la imagen del mundo" (Schaff, 1967, p. 60). En segundo lugar, el convencionalismo, en su forma radical, afirma que los juicios posibles dependen de un sistema de referencias arbitrario en relación con la experiencia, de tal forma que el conjunto de conceptos o bien el lenguaje que utilizamos determina la observación más simple efectuada sobre un objeto. Las observaciones implican la existencia de leyes que son admitidas convencionalmente, por tanto, si consideramos el lenguaje como un sistema de referencias que actúa como marco, las nociones que tenemos del mundo se encuentran determinadas por su acción en el pensamiento.

Por otra parte, la llamada hipótesis Sapir-Whorf, desde el campo de las investigaciones etnolingüísticas, se opone al carácter universal del lenguaje derivado del ámbito universal de la biología. Sapir consideró que "el lenguaje de una comunidad humana dada, que habla y piensa en esa lengua, es el organizador de su experiencia y configura su 'mundo' y su 'realidad social' gracias a esa función” (Schaff, 1967, p. 98). Su postura no implica que sea el lenguaje el elemento que determina la visión de mundo de manera creadora y arbitraria, pero sí, claramente, que tiene una función heurística que influye en nuestra percepción de la realidad al organizarla según sus categorías, como "el molde del pensamiento" (Sapir, 1994, p.30). Por su parte, Whorf, radicalizando la postura de Sapir, asimila la gramática de la lengua con su medio social, de tal forma que se destaca el principio de relatividad lingüística, convirtiendo la experiencia, inicialmente una mera corriente de impresiones, en resultado de la organización espiritual a partir del sistema lingüístico (Gil, 2001, p.87). Whorf sostendría en resumen que "la estructura global de cada lenguaje ejerce una influencia diferencial en la manera en que un hablante [...] percibe y concibe el mundo, en cómo desarrolla y emplea su propio pensamiento y en cómo se comporta ante la realidad" (Rossi Landi, 1992, p.66). Las investigaciones de Whorf se encargan de mostrar el carácter inconmensurable de las lenguas, derivado de la diferencia cualitativa en el sistema de categorías ofrecido por ellas. Las principales críticas que ha recibido la hipótesis Sapir-Whorf estriban, por un lado, en señalar que escinde el sistema de comunicación lingüística del resto de las técnicas de comunicación que existen en el medio social y el proceso de producción y reproducción social, dentro del cual justamente cobra significado el sistema de la lengua ${ }^{9}$, y por otro, la base empírica que fundamenta su postura no se ajusta en todos los casos a su interpretación (Wright, 2007).

Finalmente, cabe destacar la postura de Volóshinov quien enfatiza el estatuto eminentemente social del signo, su existencia "entre los individuos organizados, de aparecer como su ambiente, como un medio de comunicación" (2009, p.31), de lo cual colige que su investigación exige una metodología que considere su integración en la dinámica social. Asimismo, sostuvo que la conciencia misma solo obtiene su realidad por cuanto participa de la

\footnotetext{
${ }^{9}$ Rossi Landi (1992) se encarga de enumerar ocho debilidades del relativismo lingüístico. Para mayor abundamiento Cfr. Rossi Landi (1974).
}

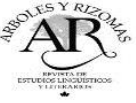


sociedad en el ámbito semiótico. En este sentido, las posturas de Vygotsky y Volóshinov parten del mismo principio, sosteniendo que no "es posible deducir la conciencia inmediatamente de la naturaleza, como intentaba hacer el ingenuo materialismo mecanicista" (Volóshinov, 2009, p.31), en confrontación con la psicología biologicista y conductista, así como también con el intento de derivar la ideología de la conciencia al modo idealista y positivista. Volóshinov pugnaba por una teoría en que la

conciencia se construye y se realiza mediante el material sígnico, creado en el proceso de la comunicación social de un colectivo organizado. La conciencia individual se alimenta de signos, crece en base a ellos, refleja en sí su lógica y sus leyes. La lógica de la conciencia es la de la comunicación ideológica, la de la interacción sígnica de una colectividad (Volóshinov, 2009, p.32).

En esta medida, la individuación se logra en el medio social de los signos y la aclaración de la conciencia se efectúa a través de los contenidos ideológicos producidos en el intercambio social (Volóshinov, 1999).

En las diversas posturas existe discrepancia en la afirmación sobre la arbitrariedad del papel activo del lenguaje. No obstante, comparten el hecho de asumir su naturaleza constructiva en el ámbito teorético, la representación del mundo. Solo en escasa medida confieren importancia al lenguaje en la individuación de la conciencia autónoma, a la configuración social del individuo y a la dependencia de lo social de la existencia individual.

\section{El lenguaje en Vygotsky}

\section{Lenguaje y funciones psicológicas superiores}

Para comprender la postura de Vygotsky deben destacarse primero dos puntos: las funciones psicológicas superiores relativas a las maneras de representar el mundo en el elemento del lenguaje, el llamado reflejo generalizado de la realidad en la conciencia, deriva, como había anticipado Marx (2010a, pp.59, 60), de los contextos sociales cuya base la conforman las interacciones humanas; el lenguaje y el pensamiento forman una unidad diferenciada.

En la primera idea se constata un doble rechazo. Por un lado, la suposición de que el ser humano es naturalmente individuo, psicológicamente egoísta en primera instancia y que luego la sociabilidad desplaza o reprime su naturaleza primaria. Al contrario de las interpretaciones de Freud e incluso Piaget ${ }^{10}$, Vygotsky asume el proceso de desarrollo como un devenir individuo en el medio social, desde una sociabilidad primaria, evidente en la orientación exterior de los bebés, hacia una sociabilidad superior que es el individuo. Por otro lado, las funciones psicológicas superiores, inherentes al ser humano, si bien tienen su base en las condiciones orgánicas del mundo biológico, no son mera prolongación de éstas, sino que representan un cambio cualitativo tributario del proceso de aprendizaje, el cual por ello ha de ser considerado como "un momento intrínsecamente necesario y universal para que se desarrollen en el niño esas características humanas no naturales, sino formadas históricamente" (Vygotsky, 2011, p.37).

Luego, el origen de la actividad consciente y del "comportamiento categorial" (Luria, 2000, p.20) es la interacción social e histórica fundadas en la comunicación lingüística, sin las

\footnotetext{
${ }^{10}$ Para un examen del propio Piaget acerca del aporte de Vygotsky, así como de la consideración que éste tuvo del autor ginebrino ver Piaget (1981).
} 
que los actos volitivos aparentemente incondicionados y las formas apriorísticas del representar teórico no tendrían lugar. Vygotsky explica este proceso como interiorización por medio del aprendizaje de funciones y estructuras.

Todas las funciones psicointelectivas superiores aparecen dos veces en el curso del desarrollo del niño: la primera vez en las actividades colectivas, en las actividades sociales, o sea, como funciones interpsíquicas; la segunda, en las actividades individuales, como propiedades internas del pensamiento del niño, o sea, como funciones intrapsíquicas. (Vygotsky et al, 2011, p.36) ${ }^{11}$

En relación con la segunda idea, Vygotsky se dedicó a mostrar que el pensamiento se realiza en el lenguaje; es decir, que ni el pensamiento se reduce a las formas verbales, ni ambos elementos son indiferentes. Puede constatarse la interacción entre ambos, dando lugar a diversas relaciones en el transcurso de su desarrollo, uno de cuyos momentos es la referencia objetal o función designativa, pero no su única relación. En efecto, el estudio del desarrollo cognitivo desde la infancia revela "la existencia de un estadio preintelectual en el proceso de formación del lenguaje y un estadio preverbal en el desarrollo del pensamiento. El pensamiento y la palabra no están relacionados entre sí a través de un vínculo primario" (Vygotsky, 2014b, p. 287). Incluso, el propio significado vehiculizado en la palabra tiene un proceso en que la índole conceptual es solo la cúspide de sus logros y caracteriza ante todo el pensamiento verbal adulto, aunque formas previas siguen desempeñando un papel en la comunicación cotidiana. En cada una de estos estadios "existe una relación diferente con el objeto y un acto diferente de inclusión del objeto en el pensamiento" (Vygotsky, 2014b, p.267).

Todo lo cual implica que el pensamiento se constituye en cuanto tal dentro de las vías de la actividad linguística, sin que por ello, no obstante, como también ha señalado Benveniste (1997), se reduzca a las formas verbales inmediatamente o, con otras palabras, "la estructura del lenguaje no es el simple reflejo especular de la estructura del pensamiento" (Vygotsky, 2014b, p. 298). El lenguaje permite el pensamiento conceptual, aunque éste no se limite a replicar la sustancia lingüística, toda vez que ella misma es también vehículo de otros procesos intelectuales, por ejemplo, mensajes expresivos, o bien, al modo señalado por Mefistófeles acerca de sendos discursos vacíos de ideas (Goethe, 2007, p.75). De hecho, la propia inadecuación inmediata de pensamiento y lenguaje es la potencia de su unidad y de la actividad intelectual propiamente tal (Vygotsky, 2014b, p.301). El curso de la palabra al pensamiento y de éste a ella se descubre en la doble orientación de la palabra, su ser para otro y su ser para sí: la estructura y función del llamado lenguaje interno en relación con el enunciado comunicativo ${ }^{12}$.

\footnotetext{
${ }^{11}$ Cursivas en el original.

${ }^{12}$ En este ámbito se encuentra una serie de problemas de índole epistemológica, centrada en el relativismo y construccionismo de la verdad, muy semejante, a fin de cuentas, del rechazo que tiene la fenomenología husserliana de la psicología, esto es, la impugnación de petitio principii, ya que si lo que conocemos se encuentra sobredeterminado por las condiciones sociales, esta propia aserción acerca de la sobredeterminación sería resultado del condicionamiento social. Esto, sin embargo, a condición de entender abstracta y mecánicamente los términos que participan de la relación. Otra forma de concebir la universalidad es la que se propone en la dialéctica, asunto que se intenta observar en este artículo a través de la superación de la pretendida distancia insalvable entre singular y universal; así también, por ejemplo, en la idea de universales históricos en Sartre (1963), o en la crítica de Pérez Soto (2008b).
} 


\section{Lenguaje y voluntad}

Con todo, aquello que nos parece aún más importante concierne al tema de la voluntad. Como es sabido, ésta ha sido concebida como un acto primario sin asidero, habitualmente como una discontinuidad con el mundo material. Desde Descartes se admitía que un área del ser humano pertenece a la res extensa, cuya explicación debe ser de causa mecánica, mientras que la conciencia obedece a una índole por completo ajena, así la voluntad se entendía como resultado de una fuerza espiritual. En efecto, la formulación kantiana de esta postura viene determinada aún más enfáticamente por la motivación inmaterial del acto moral, el cual no se deja reducir a la causalidad y la necesidad ciega de la naturaleza, sino que solo se entiende en el elemento de la libertad bajo los postulados prácticos (Kant, 2005, pp. 85 y ss.). En la psicología decimonónica y de inicios del siglo pasado, "[a]lgunos como Wundt, llamaron a esta fuerza espiritual apercepción, otros con la palabra latina "fiat", reconociendo de esta forma la participación de fuerzas espirituales en la organización de la conducta humana" (Luria, 2000, p.105). En otro extremo, sin embargo, la postura mecanicista reducía el acto voluntario a procesos más elementales, lo cual derivó en su cabal desaparición. Al no hallar una real explicación, estos psicólogos acabaron por "negarse, simplemente, a admitir el concepto mismo de acto voluntario, reduciendo toda conducta a reflejos condicionados o a hábitos" (Luria, 2000, p.105).

Por otro lado, cabe mencionar las distinciones que la filosofía analítica ha desarrollado acerca de la acción, en el marco de la teoría del derecho y la tradición filosófica que va desde Aristóteles, pasando por Kant y Hegel, hasta Wittgenstein. Aquí encontramos descripciones que buscan discernir los aspectos que permiten atribuir responsabilidad en el agente de una acción, puesto que, como ya observó Aristóteles, existen acciones involuntarias, voluntarias y otras intencionales. Estas descripciones en la actualidad se efectúan a partir de un análisis de las proposiciones que describen los actos (Ormeño, 2016). No está demás señalar que se reconocen gradaciones de responsabilidad dependiendo de los componentes cognitivos y volitivos de un acto, el grado de conocimiento que permite la deliberación del agente, así como de los motivos y deseos implicados. Fuera de lo anterior, sin embargo, lo que nos preocupa en este contexto es menos la posibilidad de describir en un acto mediante juicios analíticos ${ }^{13}$, que plantear la lógica que preside una acción cuando ésta ha rebasado la mera adaptación al medio y cuando, éste, a su vez, ha devenido objeto de la conciencia. Desde luego, esto trasunta una distinción clave respecto del lugar de las categorías teleológicas y causales dentro del ser social, para lo cual Lukács utilizó el concepto de "posición teleológica", según el cual el agente se vincula con la causalidad ciega de la naturaleza apropiando su legalidad en la actividad práctica (2016, pp. 66-71). Con todo, podría señalarse que el grado de conciencia al que aplica la explicación de Vygotsky del acto voluntario tiene que ver con la acción regulada por el propio agente, es decir, en la medida en que las operaciones mentales y corporales se encuentran sujetas a deliberación por parte del sujeto ${ }^{14}$; de aquí que Vygotsky haga énfasis en que primero las acciones se dirigen al objeto y solo posteriormente el agente toma conciencia de las acciones en cuanto tales, el tránsito del qué de la acción al cómo de ésta.

\footnotetext{
${ }^{13}$ Para una exposición sumaria de los resultados de la teorías contemporáneas de la acción en la filosofía analítica, las ciencias jurídicas, la neurociencia, entre otros, ver Ormeño, J. (Ed). (2016).

${ }^{14}$ A su vez, este tema deriva en el problema de la conciencia, sobre los actos no conscientes, etc. Respecto de las nociones de Vygotsky de conciencia, inconsciente, no conciencia y voluntad ver "Pensamiento y lenguaje" (2014b, pp. 212, 213); además del camino recorrido por sus estudios en "La conciencia como problema de la psicología", "El significado histórico de la crisis de la psicología" y "La psique, la conciencia, el inconsciente" agrupados en Vygotsky (2014a).
} 
Ahora bien, la investigación sobre el lenguaje y el pensamiento toca el problema del intelecto y la voluntad: la relación entre lo teorético y lo práctico. En efecto, la separación de ambos no puede menos que llevar a que el pensamiento "se transforme [...] en un flujo autónomo de ideas que se piensan a sí mismas, a que se segregue de toda la plenitud de la vida, de los impulsos [...] vitales del sujeto que piensa y, o bien resulte un epifenómeno completamente inútil, incapaz de modificar nada en la vida y en la conducta de la persona" (Vygotsky, 2014b, p.24). Desentrañar el estatuto del pensamiento lingüístico revela, en efecto, "la existencia de un sistema semántico dinámico, representado por la unidad de los procesos afectivos e intelectuales" (Vygotsky, 2014b, p.25). Así, fue posible para Vygotsky mostrar, primero, que la función comunicativa del lenguaje implica siempre el desarrollo de la generalización en el pensamiento. Por tanto, el mismo desarrollo del aspecto conceptual de los significados conlleva la capacidad de comunicar los mensajes. Pero este proceso del pensamiento adquiere una doble orientación, puesto que desde la aparición de aquello que Piaget denominó habla egocéntrica, el lenguaje cumple junto con la designación del mundo objetivo, un papel en la conducta. De manera que la profundización del elemento conceptual del lenguaje tiene incidencia a la vez en la capacidad que tiene el ser humano de planificar y conducir sus acciones por la vía de la voluntad. Vygotsky dirá que "con la ayuda del lenguaje [...] los niños adquieren la capacidad de ser sujetos y objetos de su propia conducta" (1995, p.51). No se trata, pues, de meros impulsos ciegos ni aquellas conductas reflejas de carácter automático, sino de aquellas cuya esencia se encuentra en el ser consciente y el comportamiento categorial.

Es sabido que en cierto grado de desarrollo la conciencia deja de ser un mero epifenómeno al servicio de la existencia biológica y la reproducción, adquiriendo un papel activo en la "posición teleológica", en acciones que van más allá de la mera adaptación al ambiente (Lukács, 2016, pp.80-82). De hecho, Marx, por ejemplo, al distinguir el trabajo realizado por el ser humano en la construcción de un edificio y la acción de las abejas en la construcción de su panal, sostenía que la clave estaba en la representación previa que efectúa el arquitecto en su conciencia y bajo cuya legalidad se subordinan las acciones realizadas por el ser humano, en contraste con la forma espontánea de la actividad en las abejas (Marx, 2010b, p.186). Ciertamente, hoy se puede discernir el psiquismo y la conciencia, considerando que muchas acciones realizadas por nosotros se efectúan en conformidad con la conciencia, mediante procesos propios de la psique, aunque no necesariamente estamos conscientes de ellos, sobre todo aquellos que se restringen a "procesos adaptativos complejos que son dirigidos por objetos del ambiente" (Leontiev, 1978, p.99). Mientras que otras acciones determinadas a modificar o hacer objetos según un modelo o representar algún contenido objetivo requieren la participación rectora de la conciencia (Leontiev, 1978, pp.100-105). En estos casos se precisa el dominio de nuestra actividad, es decir, no solo la rectificación práctica de la acción, sino que la práctica aparezca reflejada en la conciencia a fin de dirigir las acciones y "poner" la causalidad desde la voluntad (Lukács, 2016, p.71). En este ámbito, el lenguaje ocupa un lugar esencial pues por medio de éste se puede dominar el pensamiento y con ello liberar la práctica de su espontaneidad, apropiándola en el acto voluntario.

Para aclarar este punto cabe referir dos resultados de las investigaciones de Vygotsky, a saber, el lenguaje interior y los conceptos no espontáneos. 


\section{El lenguaje interior}

Lo primero que destacó Vygotsky fue que el lenguaje interior cumple una función específica y, por ende, no se limita a ser lenguaje externo inhibido. El origen del lenguaje interior ha de buscarse en el lenguaje egocéntrico, cuya característica es acompasar la actividad del infante, tanto más cuanto mayor sea el nivel de complejidad de la acción. De lo cual se concluye que el lenguaje egocéntrico solo es lenguaje interior externalizado, una etapa en la consolidación de éste, manteniendo una función y una estructura propias, las cuales consisten en organizar la conducta y la sintaxis predicativa, respectivamente. Cada vez que el ser humano debe planificar su acción con el fin de resolver problemas, actuar consciente y voluntariamente, debe someter su conducta al lenguaje interior. La historia de la mediación lingüística de la conducta está marcada por el lugar que ocupa la palabra en relación con la actividad: al inicio la palabra solo aparece después de la acción, luego junto con la acción y, finalmente, antes que ella. Lo que se observa en el habla egocéntrica en tanto antecedente del lenguaje interior, consiste en el proceso de diferenciación de las funciones del lenguaje, por cuanto el niño utiliza una misma forma tanto para las orientaciones de la palabra para sí como para otro.

Y este proceso de diferenciación ha de entenderse como el tránsito hacia la individualidad desde lo social, de lo interpsíquico a lo intrapsíquico. Así "el lenguaje egocéntrico surge en el curso de un proceso social, cuando las formas sociales de comportamiento, las formas de cooperación colectiva, se desplazan a la esfera de las funciones psicológicas individuales" (Vygotsky, 2014b, p.57). De tal forma que el dominio consciente de la acción reside en el pensamiento lingüístico, cuyo desarrollo descansa en las formas sociales de interacción. La novedad de la acción voluntaria y consciente, mediada por la función reguladora del lenguaje, frente a la conducta espontánea y biológica, tiene su base en lo social.

\section{Conceptos no espontáneos}

Ahora bien, el pensamiento alcanza un nivel todavía superior, permitiendo un dominio de sí mismo y de la práctica aún mayor, en el concepto no espontáneo, aquel que no se forma en la vivencia cotidiana, sino que depende de la enseñanza formal. Mientras que el concepto espontáneo se caracteriza por la conciencia directa del objeto, el concepto no espontáneo presenta ante la conciencia la calidad del concepto en cuanto tal. Se trata entonces de una relación distinta entre la palabra y el objeto mediante la comunidad de los conceptos. Por cierto, en el marco de estas distinciones puede insertarse la discusión acerca de los conceptos concretos y abstractos suscitada por las teorías corpóreas (Urrutia \&Vega, 2012), mostrando que son de mayor relevancia las operaciones mentales detrás de los conceptos, su interacción y papel en la conducta humana, que su origen material ya sea en la percepción y acción inmediata, bajo la forma sensualista y reduccionista, o en cierto grado de arbitrariedad cultural.

Vygotsky destacó el papel que juega la presencia del sistema en el pensamiento verbal, por cuanto a su través la conciencia alcanza conexiones supraempíricas, en contraste con las limitaciones que surgen del aislamiento de los conceptos. Cuando los niños piensan con conceptos aislados, típicos de emergencia espontánea, solo caben vínculos con los objetos señalados, relaciones empíricas. De ahí el predominio de la lógica de los actos y el sincretismo del pensamiento infantil. Pero con la adquisición de los conceptos no espontáneos, cuya característica esencial es su naturaleza sistemática, el pensamiento se conduce por relaciones entre los conceptos que mediatizan el vínculo con los objetos, lo que implica la preponderancia 
de la lógica y lo suprasensible. La interacción recíproca entre los conceptos espontáneos y no espontáneos resulta del aporte que cada uno hace al otro: los no espontáneos permiten la toma de consciencia de los espontáneos, y éstos la saturación de contenido sensible de aquellos. Por cierto que la base del desarrollo de los conceptos no espontáneos es la estructura alcanzada en los cotidianos.

Pero lo esencial de los resultados logrados en la investigación de estos conceptos consiste en la relación constatable entre sistema y voluntad. Cuando a un niño se le presentan tareas en que han de usar conceptos espontáneos, su reacción intelectual característica es inferior, carente de lógica, generalización y consistencia. Mientras que cuando la tarea implica el uso de conceptos no espontáneos integrados inherentemente en relaciones sistemáticas con otros conceptos, su reacción es claramente superior, consistente. Por su naturaleza, y en consideración de la ley de Claparède sobre la toma de conciencia, el concepto cotidiano es no consciente $\mathrm{y}$, por tanto, su utilización no es apropiada para una tarea voluntaria. Así, la "espontaneidad y el carácter a-consciente del concepto, la espontaneidad y la carencia de sistema son sinónimos ${ }^{15 "}$ (Vygotsky, 2014b, p. 277). La novedad del sistema en el desarrollo del pensamiento del ser humano consiste en la operación voluntaria con conceptos. En tanto generalización, el concepto alcanza su desarrollo efectivamente tal en una organización jerárquica y vertical solo con el aprendizaje del sistema de conceptos no espontáneos que, a su vez, reestructura la función de los conceptos cotidianos $\mathrm{y}$, por ende, la experiencia vital inmediata.

\section{Inteligibilidad de la teoría del lenguaje de Vygotsky en relación con Hegel}

\section{Marco general de interpretación: unidad de singular y universal}

Sostenemos que el concepto de espíritu de Hegel permite asumir el tema central de la empresa teórica de Vygotsky, pese a que el autor ruso adhiere explícitamente al materialismo histórico en el desarrollo de lo que llamó psicología dialéctica, a saber, la función de la sociedad en los procesos de individuación. En este camino resulta esclarecedor el papel que ocupa el lenguaje. No solo en aquello que fue recalcado por el llamado giro lingüístico; esto es, la estructura profunda del lenguaje y, por ende, las prácticas textuales que fundamentan socialmente los discursos, oscurecidas en el intercambio de significantes: las determinaciones sociales que sustentan la apariencia de subjetividad, entendida como individuo. Se trata más bien del lenguaje como proceso en que lo social se desarrolla en la medida en que constituye la individualidad, pero cuya función y contenido por inherencia no se deja reducir a su condición.

La actividad consciente, pese a su desarrollo tardío en relación con la práctica, incluso con la inteligencia, no se reduce a replicar los factores que le dan origen. La conciencia deja de ser un mero epifenómeno del desarrollo biológico y de la inteligencia mecánica. Hegel diría que el resultado no se limita a desplegar la sustancia. Aquel comportamiento específicamente humano, la actividad voluntaria y consciente, está marcado estructuralmente por el desplazamiento del lugar que ocupa el lenguaje interior, presentándose finalmente al inicio de la acción teleológica.

Ahora bien, este despliegue de lo social desde lo social primario puede entenderse como el tránsito de una primera universalidad abstracta, solo en sí, a una universalidad concreta, también para sí. Desde luego, aquello que Vygotsky desdeñaba de las teorías que suponen al ser humano originariamente individual o egocéntrico, consiste en su falta de reconocimiento del aspecto genérico natural del ser humano, el carácter de su especie. Pero resulta también evidente

${ }^{15}$ Itálicas del autor.

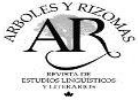


que en este ámbito, la universalidad de la especie coincide con el ser individual. Esta primera etapa es la sociedad ciega del individuo, la mera sociedad como género en sí o, según Hegel, como un individuo orgánico en que la universalidad es todavía inmediata (Hegel, 2009, p.177). El curso de desarrollo de las potencialidades de estos ámbitos hasta aquí indiferenciados, no es otra cosa que el organismo natural, base pero no explicación de la persona humana y sus funciones específicas. Podemos decir que en este nivel en sí, la sociedad se presenta en el individuo y coincide con él como una fuerza ciega que esconde su historia.

En las prácticas sociales, en el marco cultural de las interacciones que se dan entre adultos y niños, sin embargo, se abre el ser individual de la especie a su individuación para sí, lo universal concreto y mediada. Y esta emergencia de la personalidad humana por cuanto toma conciencia de sí, estriba en un proceso social. La profundización de lo social en el individuo es su individuación, es decir, el acto voluntario y la definición de sus contenidos. Todo este proceso social de individuación se efectúa en el campo eminentemente transindividual del lenguaje. La potencia lingüística permite la apropiación de la densidad social en el individuo, convirtiendo las funciones sociales en funciones internas e individuales, no como un contenido pasivo, sino como actividad autónomamente regulada. La universalidad del lenguaje comporta funciones que escapan a la mera confirmación de su estructura, de su sustancia, dando lugar a la novedad del comportamiento humano social.

En el lenguaje el ser humano realiza el pensamiento y en sus vías puede alcanzar una claridad cada vez mayor de sí mismo, adquiriendo el dominio de sus funciones intelectuales superiores, lo cual, a su vez, permite que su actividad categorial enriquezca sus resultados.

Cuando nos representamos a lo universal, la totalidad social, como un elemento externo que incide en un individuo original no podemos menos que enredarnos en las aporías que intentan unir lo que ya ha sido concebido desde el inicio como una relación independiente e, incluso, indiferente. Pero si concebimos la universalidad social, en este caso, el lenguaje, como una entidad que solo existe en los individuos hablantes, a la vez que éstos consiguen su individualidad precisamente en el ámbito de lo universal, comprendemos que los términos son inescindibles puesto que solo tienen realidad como polos de una relación constituyente. Tanto más importante es este asunto, cuanto que la implicación de singular y universal no reside en la inmediatez de la especie, sino en la mediada autoconciencia, la particularidad. Esto significa que lo singular debe negarse como tal para adquirir la particularidad, de lo contrario no pasa de ser una abstracta universalidad, la naturaleza orgánica, la expresión de funciones primarias de todo animal, a la vez que, por su parte, lo universal solo vive como particular.

En la actividad lingüísticamente mediada del ser humano, por tanto, podemos encontrar una totalidad concreta -en el concepto hegeliano de espíritu-, la unión de los extremos de individuo y sociedad, toda vez que las funciones autónomas eminentemente personales, tales como la libre acción voluntaria y el pensamiento, no son sino funciones adquiridas en el campo de lo social. Más aún, estos extremos solo tienen realidad como expresión de la relación que los fundamenta.

\section{Teoría y práctica}

Dos consecuencias se desprenden de este marco general de interpretación de la teoría del lenguaje de Vygotsky. Primero, que aquello que puede denominarse volición en cuanto tal, como acto superior del ser humano, depende menos de pulsiones y fuerzas ocultas, ya sean naturales o espirituales, que de una práctica cuya base material la encontramos en la cultura. Si bien se puede 
reconocer la existencia de distintos instintos y actos reflejos presentes en la acción humana, aquello que toma la forma idónea de actividad consciente descansa en una función propia del pensamiento verbal, una función que debe concebirse como un resultado que excede la sustancia que se encuentra a su base. Pensamos que esta es una manera clara de comprender la llamada voluntad racional.

Por otro lado, según hemos visto, la designación del objeto a través de la palabra, su aspecto teorético, es a la vez su estatuto práctico, su aspecto volitivo. La profundización de la generalización, el nivel conceptual de la palabra y, luego, su sistematización como concepto no espontáneo, implican también la voluntad, el dominio de sí y la consciencia de sí, a condición de que no se entiendan estos vínculos según una representación mecánica de reducción lineal de ambas esferas, sino conforme a la dialéctica propugnada por Vygotsky. Por tanto, lejos de unirse solo ulteriormente las esferas teorética y práctica del ser humano, el desarrollo de cada una es un mismo desarrollo. La profundización del elemento teórico en el lenguaje es él mismo profundización de la práctica, la volición. Asunto que hoy adquiere relevancia en discusiones filosóficas sobre la educación como en Rancière (2010), quien enfatiza que detrás de la inteligencia se encuentra la voluntad de atender a desafíos prácticos, por tanto, el desarrollo intelectual indica la voluntad de ese desarrollo.

\section{Conclusión}

A partir de las consideraciones precedentes se puede establecer una argumentación que afirme el papel activo del lenguaje en los ámbitos del pensamiento teorético, volcado hacia el objeto, y el comportamiento categorial, es decir, de la actividad consciente y voluntaria, donde el mismo puede asumirse como una mediación necesaria de los actos propiamente humanos, aunque no una carga determinante. Es más, las acusadas inercias de la actividad lingüística y sus estructuras subyacentes, cuando no se prefiere solo callar frente a ello como en Wittgenstein (2009, p.137), han de subvertirse por un pensamiento que asume al lenguaje mismo como su elemento y no a través de la búsqueda de una salida al margen de éste, ya sea en una pretendida alternativa prelingüística, supralingüística o, incluso, retorciendo las propiedades del discurso a fin de extraer de ello subrepticiamente una verdad inefable. Para ello se ha de notar en primer lugar que la escisión entre lenguaje y pensamiento es producto justamente del desarrollo lingüístico del pensamiento, cuya operación se manifiesta como una condición básica del trabajo intelectual. Por ello las requisitorias acerca de la falta de coincidencia (Rivano, 1960) deben desestimarse, puesto que ella misma concierne justamente a la potencia del pensamiento y no a su límite, como queda manifiesto incluso en la experiencia de pensadores como Kant que vio en la dilucidación verbal un paso necesario del ejercicio del pensamiento (2007, pp.393 ss.).

En segundo lugar, la misma voluntad, incluyendo el rechazo al lenguaje no puede efectuarse en su plena dimensión más que por la vía lingüística. Lo que implica que la misma individualidad inherente a la acción voluntaria encuentra su fundamento en la profundización de la índole social del ser humano, antes que en una función primaria determinada biológicamente, o peor aún, como salto irracional.

Por cierto, todas estas observaciones pueden impugnarse si se rechaza la base materialista del planteamiento. Si se rebate todo aspecto fáctico, temporal y espacial del sujeto, como por ejemplo en el idealismo de Schelling (2005) cuando escinde la autoconciencia en pura y empírica, o al modo fenomenológico de ascendiente husserliana, entonces el estatuto del pensamiento y la voluntad no aparecen vinculadas a su emergencia y desarrollo, antes al 
contrario, se esconden así sus determinaciones históricas y culturales (Adorno, 2017, pp.277284). Pero si tomamos el lenguaje y el pensamiento en su proceso, genéticamente, podemos constatar su interacción recíproca y el valor que tiene esta relación respecto de las producciones intelectuales y prácticas en el ser social del individuo.

\section{Bibliografía}

Adorno, T. (2017). Ontología y dialéctica. Lecciones sobre la filosofía de Heidegger. Buenos Aires: Eterna cadencia.

Badiou, A. (2014). La aventura de la filosofía francesa. Santiago: Lom.

Benveniste, E. (1997). Categorías de pensamiento y categorías de la lengua. Problemas de lingüística general I. México D.F.: Siglo XXI.

Cassirer, E. (2016). Filosofía de las formas simbólicas. I. El lenguaje. México D.F.: FCE.

Cole, M., \& Wertsch, J. (1996), Beyond the Individual. Social Antinomy in Discussions of Piaget and Vygotsky. Human Development, 39(5), 250-256. https://doi.org/10.1159/000278475

Dri, R. (2007). Hegel y la lógica de la liberación. Buenos Aires: Biblos.

Duque, F. (2015). La era de la crítica. Madrid: Akal.

Gadamer, H. G. (2011). La dialéctica de Hegel. Madrid: Cátedra.

Gil, J. M. (2001). Introducción a las teorías lingüísticas del siglo XX. Santiago: Ril.

Goethe, J. W. (2007). Fausto. (Felipe Ruiz Noriega Trad.). Madrid: Edaf.

Habermas, J. (1990). Pensamiento posmetafísico. México D.F.: Taurus.

Habermas, J. (1994). El discurso filosófico de la modernidad. Madrid: Taurus.

Habermas, J. (2015a). Teoría y praxis. Madrid: Tecnos.

Habermas, J. (2015b). Ciencia y técnica como ideología. Madrid: Tecnos.

Hegel, G.W.F. (1999). Enciclopedia de las ciencias filosóficas. Madrid: Alianza.

Hegel, G.W.F. (2006). Filosofía real. Madrid: FCE.

Hegel, G.W.F. (2007). Lecciones de estética. Madrid: Akal.

Hegel, G.W.F. (2009). Fenomenología del espíritu. Buenos Aires: FCE.

Heidegger, M. (1994). Poéticamente habita el hombre. Conferencias y artículos. Barcelona: Ediciones del Serbal.

Henrich, D. (1990). Hegel en su contexto. Caracas: Monte Ávila.

Iliénkov, E. (2017). Pensamiento y lenguaje en Hegel. Recuperado de https://marxismocritico.com/2017/06/23/pensamiento-y-lenguaje-en-hegel/

Kant, I. (2005). Crítica de la razón práctica. (Ed. Bilingüe). México D.F.: FCE.

Kant, I. (2007). Crítica de la razón pura. (Mario Caimi trad.). Buenos Aires: Coligue.

Labarriere, P. J. (1985). La fenomenología del espíritu de Hegel. México D.F.: FCE.

Lefebre, H. (1967). Lenguaje y sociedad. Buenos Aires: Proteo.

Leontiev, A.N. (1978). Actividad, conciencia y personalidad. Buenos Aires: Nueva Visión.

Lukács, G. (1969). Prolegómenos a una estética marxista. Barcelona: Grijalbo.

Lukács, G. (2016). Ontología del ser social. El trabajo. Buenos Aires: Herramienta.

Luria, A.R. (2000). Conciencia y lenguaje. Madrid: Visor Dis.

Marcuse, H. (2017). Razón y revolución. Madrid: Alianza.

Marx, K. (2010a). La ideología alemana (I) y otros escritos filosóficos. Buenos Aires: Losada.

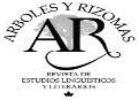


Marx, K. (2010b). El capital. Crítica de la economía política. Tomo I. (Cristian Fazio C. Trad.). Santiago: Lom.

Ormeño, J. (Ed). (2016). Acciones, razones y agentes. Santiago: Lom.

Pérez Soto, C. (2008a). Desde Hegel. México D.F.: Ítaca.

Pérez Soto, C. (2008b). Sobre un concepto histórico de ciencia. Santiago: Lom.

Piaget. J. (1981). Comentarios sobre las observaciones críticas de Vygotsky. Journal for the Study of Education and Development, 4(1), 37-48. https://doi.org/10.1080/02103702.1981.10821887

Rancière, J. (2010). El maestro ignorante. Barcelona: Laertes.

Rivano, J. (1960). Experiencia del error y doctrina del conocimiento. Revista de Filosofía. 7(1-2), 93-136.

Rossi Landi, F. (1992). El lenguaje. En R. Williams (Ed.) Historia de la comunicación Vol.1. (pp.45-83). Barcelona: Bosch.

Rossi Landi, F. (1974). Ideología de la relatividad lingüística. Barcelona: Nueva Visión. https://doi.org/10.1515/9783110812893

Sapir, E. (1994). El lenguaje. México D.F.: FCE.

Sapir, E. (2013). El lenguaje. Introducción al estudio del habla. México D.F.: FCE.

Sartre, J.P. (1963). Crítica de la razón dialéctica. Libro I. Buenos Aires: Losada.

Schaff, A. (1967). Lenguaje y conocimiento. México D.F.: Grijalbo.

Schelling, F. (2005). Sistema del idealismo trascendental. Barcelona: Anthropos.

Seve, L. (2013). Del caso Bajtín al caso Vigotsky. Marx pensador de la individualidad humana. Recuperado de https://marxismocritico.com/2013/12/30/del-caso-bajtin-al-caso-vigotsky

Simon, J. (1982). El problema del lenguaje en Hegel. Madrid: Taurus.

Taylor, Ch. (2005). La libertad de los modernos. Buenos Aires: Amorrortu.

Taylor, Ch. (2014). Hegel y la sociedad moderna. México D.F.: FCE.

Urrutia, M., \& De Vega, M. (2012). Lenguaje y acción. Una revisión actual a las teorías corpóreas. Revista de lingüística aplicada y teórica, 50(1), 39-67. https://doi.org/10.4067/S0718-48832012000100003

Valls Plana, R. (1994). Del yo al nosotros. Barcelona: PPU.

Vygotsky, L.S., Leontiev, A. y Luria, A. (2011). Psicología y pedagogía. Madrid: Akal.

Vygotsky, L.S. (1995). El desarrollo de los procesos psicológicos superiores. Barcelona: Crítica. Vygotsky, L.S. (2010). Teoría de las emociones. Madrid: Akal.

Vygotsky, L.S. (2014a). Obras escogidas. Vol I. Madrid: Machado.

Vygotsky, L.S. (2014b). Obras escogidas. Vol. II. Madrid: Machado.

Volóshinov, V. (2009). El marxismo y la filosofía del lenguaje. Buenos Aires: Godot.

Volóshinov, V. (1999). Freudismo. Un bosquejo crítico. Buenos Aires: Paidós.

Wittgenstein, L. (2009). Tractatus logico-philosophicus. Investigaciones filosóficas. Sobre la certeza. Madrid: Gredos.

Wright, D. (2007). La hipótesis Sapir-Whorf: una evaluación crítica. Revista Caleidoscopio, 2, 726. https://doi.org/10.33064/22crscsh369

Žižek, S. (2015). Introducción. Menos que nada. Hegel y la sombra del materialismo dialéctico. Madrid: Akal. 